\title{
Peptídeos Bioativos de Soja Glycine Max (L.) Merrill: uma Breve Revisão
}

\author{
Carolina S. B. Damasceno, Letícia F. de Oliveira, \\ Marilis D. Miguel \& Obdulio G. Miguel
}

A soja é a principal cultura no agronegócio brasileiro, incorporada aos poucos no cerrado, levou o Centro-Oeste a se tornar uns dos maiores produtores do grão, especificamente, o estado de Goiás, que se encontra entre os maiores produtores nacionais. A soja possui grande importância nutricional, devido ao teor proteico, entretanto, no processamento, a fragmentação proteica gera peptídeos, que podem exercer funções biológicas e serem denominados bioativos. Nesse contexto, esta revisão buscou enfatizar a importância dos peptídeos bioativos de soja e suas principais propriedades funcionais, verificando-se, assim, que estes podem ser explorados pela indústria alimentícia, na busca de alimentos com apelos funcionais.

Palavras-chave: cerrado; agronegócio; propriedades funcionais.

Soya is the main crop in Brazilian agribusiness, incorporated gradually at the savana, induced the Midwest region to become one of the largest soybean producers, specifically, the state of Goiás, which is among the largest national producers. Soybean has great importance due to nutritional protein content, however, in the processing, the protein fragmentation generates peptides, that can exert biological functions and are called bioactive. In this context, this review search to emphasize the importance of bioactive peptides from soybean and its main functional properties, verifying, that these can be exploited by the food industry, in food search with functional appeal.

Keywords: Savanna; agrobusiness; functional properties. 


\section{Introdução}

O cultivo da soja (Glycine max (L.) Merrill), família Fabaceae, no Brasil e, sobretudo, na região do Cerrado, adquiriu grande importância econômica e política a partir de 1990, em virtude do crescimento da demanda interna e externa de grãos, farelo e óleo ${ }^{1,2,3}$. Dois fatores foram os principais responsáveis por esta expansão. Primeiro, a Europa passou a demandar uma quantidade maior de soja para a alimentação bovina, depois da crise da vaca louca do final da década de 1980 e também para o consumo humano em virtude da substituição do consumo cárneo pela proteína de soja. Em segundo lugar, a China após sua entrada no mercado consumidor internacional, em 2001, tornou-se um dos maiores importadores de soja brasileira, consolidando sua adesão à Organização Mundial do Comércio (OMC) $)^{2,3,4}$.

Em função da exportação da soja, pesquisas para o desenvolvimento de cultivares mais resistentes e programas de engenharia genética têm sido estimulados, a fim de aumentar a produtividade e fortalecer o agronegócio brasileiro. Entre as leguminosas, a soja destaca-se, pela importância nutricional inerente ao teor proteico de $40 \%$, superior aos demais cereais. A hidrólise proteica desta pode gerar peptídeos, considerados compostos bioativos utilizados na nutrição funcional, devido os benefícios à saúde e à melhoria da qualidade de vida, representando moléculas de grande interesse para a indústria alimentícia e farmacêutica.

A funcionalidade desses peptídeos oriundos da soja possuem atividade baseada na sequência de aminoácidos ${ }^{5,6}$. Estes peptídeos podem atuar em diversas biológicas, como anti-hipertensiva, antitrombótica, antioxidante, antitumoral e no tratamento de inflamações cutâneas ${ }^{7,8}$. Os peptídeos também tornaram-se importantes para a indústria de cosméticos, como ingredientes ativos, devido ao seu potencial antioxidante e fácil absorção ${ }^{9,10}$. Além da capacidade de regenerar a matriz extracelular, aumentando a produção de colágeno ${ }^{11}$.

Neste contexto, devido ao alto teor proteico da soja, vários estudos têm focado o potencial dessa leguminosa na formação de peptídeos bioativos. Portanto, esta revisão, tem como objetivo fazer um levantamento da importância econômica da soja no Brasil, especificamente no estado de Goiás, bem como as principais propriedades funcionais dos peptídeos bioativos oriundos da soja.

\section{Levantamento Bibliográfico}

\section{A PRODUÇÃO DE SOJA NO BRASIL E NO ESTADO DE GOIÁS}

A cadeia produtiva da soja é a mais bem-sucedida no agronegócio brasileiro, ofertando grãos, farelos e óleos para o abastecimento do mercado interno e externo ${ }^{12}$. A crescente produtividade dessa oleaginosa devese à utilização de tecnologia adequada por parte dos produtores e às pesquisas para obtenção de cultivares mais produtivas e resistentes às condições adversas no cultivo $^{13}$.

O cultivo da soja no Brasil teve início na década de 1960, na região Sul do país, como cultura de verão em sucessão ao trigo, expandindo-se para outras regiões, atingindo o Cerrado e hoje vem atingindo o bioma amazônico. Há anos que o complexo: soja, grão, óleo e farelo, estabeleceu-se, como a principal atividade agropecuária do país, pela sua importância tanto territorial, como econômico-comercial ${ }^{14,15}$. Atualmente, o Brasil encontra-se em segundo lugar no ranking de maior produtor e primeiro, como exportador de soja a nível mundial ${ }^{16}$.

A partir da década de 70 , com a expansão e modernização da agricultura, em quase todo o território nacional, o cerrado goiano também passou por importantes transformações. Alguns fatores contribuíram para a modernização da agricultura no estado de Goiás, destacando-se o rodoviarismo, a construção de Goiânia e Brasília (DF), e os programas Polocentro (Programa de Desenvolvimento dos Cerrados) e Proceder (Programa de Cooperação Nipo-brasileira para o Desenvolvimento dos Cerrados) $)^{17}$.

Neste contexto, o cerrado foi incorporado gradativamente ao processo de modernização, tornandose atrativo para a produção de soja, favorecendo o aumento na demanda pelo produto nos mercados internacionais. Dessa forma, o cerrado goiano passa a ter alta produtividade, exportando excedentes consideráveis para o país e para o exterior ${ }^{18}$. A ocupação das áreas de cerrado resultou na alteração do perfil da região, levando à mecanização da zona rural, com a pecuária extensiva e cultura de exportação e ao crescimento instantâneo da zona urbana, bem como o próprio cerrado sofreu grandes alterações no seu conteúdo, dando espaço às 
culturas de soja, milho, algodão, tomate, sorgo, canade-açúcar ou vastas áreas cobertas por pastagens ${ }^{19,20}$. Observa-se que o estado de Goiás, ao longo dos últimos anos, tem se especializado cada vez mais nas culturas da soja e da cana-de-açúcar. Nesse sentido, a região Centro-Oeste tornou-se referência nacional como área de grande potencial agrícola, principalmente na produção de grãos ${ }^{20,21}$.

A região do Cerrado brasileiro destaca-se como um polo nacional na produção de grãos ${ }^{22}$. Segundo a Companhia Nacional de Abastecimento (CONAB), a Região Centro-Oeste, principal produtora da oleaginosa no país, confirmou o incremento de $4,5 \%$ em relação à safra de 2014/2015, apresentando a maior produtividade em relação aos demais estados brasileiros (Gráfico 1). O estado de Goiás ocupa a quarta posição no cenário nacional quanto à produção e o segundo lugar no CentroOeste, perdendo apenas para o estado de Mato Grosso (Grafico 2) ${ }^{1}$.

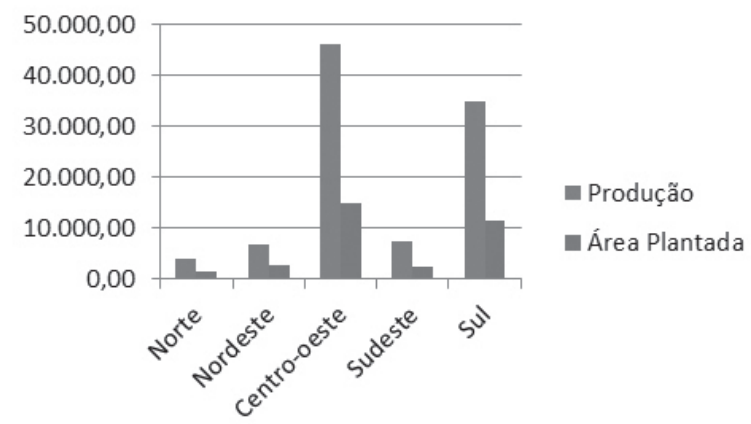

Gráfico 1: Comparativo de Produção de soja (em mil t) e Área plantada (em mil há), nas safras de 2015/2016, entre as regiões brasileiras. Dados: Conab (2016).

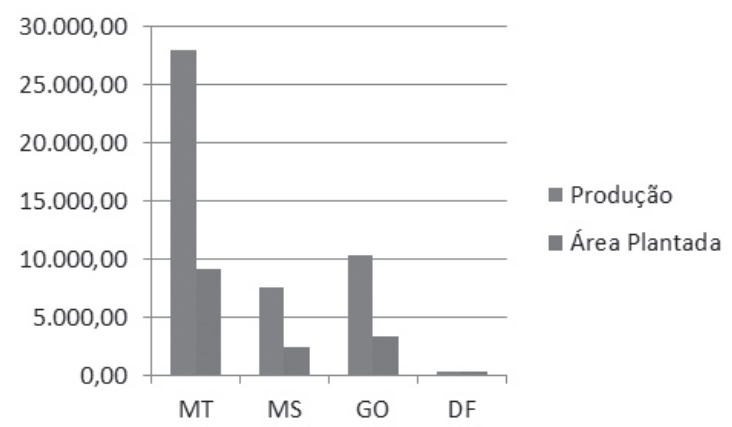

Gráfico 2: Comparativo de Produção de soja (em mil t) e Área plantada (em mil há), nas safras de 2015/2016, nos estados da região CentroOeste. Dados: Conab (2016).
Embora o excesso de chuvas e falta de luminosidade no início de janeiro de 2016 tenham prejudicado o enchimento de grãos, houve aumento de $18,8 \%$ na produção da soja em relação à safra de 2014/2105 no território goiano. Segundo levantamento do CONAB $^{1}$, para a safra de 2015/2016, para uma colheita de $65 \%$ da área plantada no leste goiano houve produtividade média de 56 sacas/ hectare; no sudoeste foi estimada a produtividade média de 55 sacas/hectare de aproximadamente $85 \%$ das lavouras colhidas; no sul e centro-oeste goiano houve uma média produtiva de 53 sacas/hectare para $80 \%$ e $90 \%$ de área colhida respectivamente. O norte goiano apresentou cerca de $50 \%$ colhido com uma produtividade média de $52 \mathrm{sc} / \mathrm{ha}$.

\section{SOJA COMO ALIMENTO FUNCIONAL}

Os alimentos funcionais são aqueles que, além de contribuir com a nutrição, contêm substâncias que podem ser consideradas biologicamente ativas, produtoras de benefícios clínicos ou de saúde. São capazes de reduzir o risco de algumas doenças e auxiliar em funções fisiológicas do organismo $^{23}$. Essa classe de alimentos contém substâncias capazes de modular as respostas metabólicas do indivíduo, resultando em maior proteção e estímulo à saúde. Promovem o bem-estar dos indivíduos, prevenindo $\mathrm{o}$ aparecimento precoce de doenças degenerativas e permitindo o aumento da longevidade com qualidade de vida. Portanto, são alimentos que contêm uma ou mais substâncias capazes de atuar no metabolismo ou na fisiologia do ser humano, promovendo benefícios à saúde ${ }^{24}$.

As substâncias ou compostos funcionais caracterizamse por apresentar propriedades que são benéficas ao ser humano como, por exemplo, a ação antioxidante ${ }^{25}$. A presença desses componentes nos alimentos é vista como vantagem, que deve ser informada ao consumidor e pode impactar a comercialização do produto. $\mathrm{O}$ órgão norteamericano que regulamenta alimentos e medicamentos, FDA (Food and Drug Administration), aprovou, em 1999. uma alegação funcional em rótulos de produtos enriquecidos com proteína de soja, relacionando-os à redução do LDL-colesterol e do teor de colesterol total, atuando na prevenção de doenças cardiovasculares ${ }^{26 .}$ Esses produtos incluem alimentos compostos ou derivados de soja integral e alimentos que contêm ingredientes proteicos de soja. 
O Brasil, como segundo maior produtor mundial de soja, apresenta enorme potencial para participação no crescente mercado dos alimentos funcionais. Nesse sentido, a ANVISA (Agência Nacional de Vigilância Sanitária) atualizou, em janeiro de 2005, a lista de produtos com alegação de benefícios à saúde. São substâncias com propriedades funcionais, de saúde, novos alimentos ou ingredientes, substâncias bioativas e probióticos. Para a proteína de soja pode constar a alegação "o consumo diário de no mínimo $25 \mathrm{~g}$ de proteína de soja pode ajudar a reduzir o colesterol. Seu consumo deve estar associado a uma dieta equilibrada e hábitos de vida saudáveis", e determina que o rótulo apresente a quantidade de proteína de soja contida na porção diária do produto pronto para consumo, próximo a alegação ${ }^{27}$.

\section{PEPTÍDEOS BIOATIVOS}

A palavra "peptídeo" vem do termo grego, traduzida como "pequenas partes digeridas". Estruturalmente, os peptídeos são curtas cadeias de aminoácidos ligados através de ligações peptídicas. Uma ou mais subunidades de polipeptídios constituem uma molécula de proteína. As proteínas são componentes essenciais dos tecidos em organismos biológicos e participam em um grande número de processos fisiológicos no interior das células. Nos alimentos, as proteínas constituem um macronutriente importante, que serve como fonte de energia e aminoácidos, essenciais para crescimento e manutenção normal do corpo. As proteínas também são responsáveis por várias propriedades físico-químicas e sensorial nos alimentos e podendo também atuar como ingrediente funcional na promoção da saúde ${ }^{28,29}$.

Um papel importante das proteínas, reconhecido mais recentemente, é o regulador que peptídeos originários da proteína podem ter no organismo humano. Esses peptídeos, que são fragmentos específicos de proteínas, ocorrem naturalmente no alimento, no seu processamento ou pela digestão incompleta da proteína no sistema digestório e são absorvidos como tal. Alguns desses peptídeos possuem um impacto positivo nas condições e funções corporais, podendo influenciar na saúde ${ }^{30}$.

As proteínas hidrolisadas podem ser obtidas mediante a ação de enzimas, resultando em peptídeos e aminoácidos livres ${ }^{31}$, podendo assim apresentar propriedades bioativas $^{32}$.

\section{OBTENÇÃO DE PEPTÍDEOS BIOATIVOS}

Os peptídeos bioativos são considerados inativos quando "presos" à sequência proteica, mas irão exercer funções específicas após sua liberação da cadeia proteica pelas enzimas digestivas durante o trânsito gastrointestinal, fermentação ou amadurecimento, processamento de alimentos e ainda por enzimas derivadas de micro-organismos ou plantas, sendo a hidrólise enzimática a maneira mais comum para a produção de peptídeos bioativos ${ }^{6,33}$.

A hidrólise química é um processo de difícil controle, que origina produtos com reduzida qualidade nutricional, devido à formação de D-aminoácidos e de substâncias tóxicas, como a lisinoalanina. Portanto, a hidrólise enzimática apresenta uma série de vantagens sobre a hidrólise química, como especificidade, controle do grau de hidrólise, condições moderadas de ação, disponibilidade comercial em larga escala, custo moderado, menor teor de sal no produto final e formação mínima de subprodutos ${ }^{34}$.

Uma desvantagem encontrada no processo de hidrólise enzimática é o desenvolvimento de sabor amargo no decorrer da catálise, o qual parece estar relacionado à liberação de grupamentos hidrofóbicos que se encontravam no interior das moléculas proteicas. Esta característica representa um dos principais obstáculos na aplicação generalizada dos hidrolisados. Uma forma de resolver esta questão, bem como de proteger estes compostos contra a degradação enzimática gástrica ou intestinal, seria através da microencapsulação desses ${ }^{35}$.

A fermentação microbiana representa outro processo de obtenção de peptídeos bioativos podendo ser natural ou controlada. A fermentação microbiana envolve culturas iniciadoras de produtos lácteos, usadas industrialmente, com capacidade proteolítica. Tratam-se de bactérias ácido - lácticas, que degradam proteínas do seu meio circundante quando do seu crescimento, levando à produção de sequências de aminoácidos ou de aminoácidos livres. $\mathrm{O}$ grau de proteólise depende das espécies envolvidas, bem como, das condições físicas em que decorre a fermentação. Esta propriedade é tradicionalmente explorada pela indústria alimentar, uma vez que os peptídeos e os aminoácidos resultantes da degradação das proteínas do leite, durante a fermentação, contribuem para o flavor, o aroma e a textura típica dos produtos ${ }^{36}$. 
Os peptídeos podem ser rapidamente hidrolisados em presença das proteases presentes em nosso organismo, e podem apresentar baixa atividade oral e plasmática ${ }^{37}$. Outras características relacionadas à dificuldade de transporte, excreção rápida pelo fígado ou rins e baixa seletividade podem também dificultar sua utilização terapêutica. Este conhecimento tem despertado estudos que através de deleção, adição e modificação racional da sequência de aminoácidos, grupos ionizáveis e/ou esqueleto peptídico visam desenvolver análogos de peptídeos biologicamente ativos com propriedades físicas e químicas capazes de agonizar ou antagonizar as suas ações, aumentar ou diminuir as suas potências e alterar as suas estabilidades frente a proteases e/ou seletividades. Este tipo de estudo é chamado de exploração da relaçãoestrutura atividade (SAR) e depende exclusivamente da síntese de peptídeos. Muitas vezes, entretanto, o estudo de SAR de um peptídeo biologicamente ativo tem como único objetivo elucidar o modo de ação desse.

Em linhas gerais, os análogos sintéticos são inicialmente obtidos para determinar a contribuição individual de cada um dos aminoácidos da sequência natural na expressão da atividade biológica. Em etapa posterior, é definido como as cadeias laterais essenciais à atividade devem estar dispostas espacialmente. $\mathrm{O}$ objetivo final é a obtenção, mediante sínteses individuais e paralelas ou pela química combinatória, de estruturas parcial ou totalmente isentas de esqueleto peptídico (peptidomiméticos), que possam ser usadas como drogas. A exploração de SAR de vários hormônios peptídicos tem gerado compostos comerciais utilizados de forma terapêutica. Recentemente, também os peptídeos antimicrobianos passaram a ser estudados usando esta abordagem $^{37}$.

Peptídeos bioativos podem também se originar de proteínas endógenas, aumentando, assim, as funções reguladoras das proteínas codificadas pelo genoma. A esse proteoma específico foi atribuído o nome de "criptoma", pois codifica “criptídeos" (do Inglês 'cryptides'), peptídeos bioativos 'escondidos' nas proteínas endógenas, liberados após sua digestão parcial ${ }^{38}$. Por extensão, os peptídeos bioativos de alimentos também vêm sendo descritos como "encriptados" (do Inglês 'encrypted') na sequência original, sendo liberados tanto pelo processamento como pela digestão incompleta da proteína no trato digestório. Esta é uma área em franco desenvolvimento e novos peptídeos e suas funções vêm sendo descritos na literatura, tanto de origem endógena como proveniente dos alimentos.

\section{FUNÇÕES DOS PEPTÍDEOS BIOATIVOS}

Os principais sistemas de corpo, ou seja, o cardiovascular, digestivo, imunológico e sistema nervoso, podem ser afetados pelos peptídeos bioativos (Tabela 1), dependendo da sua sequência de aminoácidos. Por esta razão, o potencial dos peptídeos bioativos na promoção da saúde humana, reduzindo o risco de doenças crônicas ou aumentando a proteção imune natural tem despertado um grande interesse científico nos últimos anos. Estes efeitos benéficos para a saúde podem ser atribuídos a inúmeras sequências peptídicas conhecidas exibindo, por exemplo, ação antimicrobianas, antioxidante, anti-trombótica, antihipertensiva e atividades imunomoduladoras. A atividade desses peptídeos é baseada na composição inerente ao aminoácido e à sequência desses. $\mathrm{O}$ tamanho das sequências ativas pode variar desde dois a vinte resíduos de aminoácidos ${ }^{5,6}$.

Tabela 1. Principais funções dos peptídeos bioativos

\begin{tabular}{|l|l|l|l|}
\hline $\begin{array}{l}\text { Sistema } \\
\text { Cardiovascular }\end{array}$ & $\begin{array}{l}\text { Sistema } \\
\text { Nervoso }\end{array}$ & $\begin{array}{l}\text { Sistema } \\
\text { Digestório }\end{array}$ & $\begin{array}{c}\text { Sistema } \\
\text { Imunológico }\end{array}$ \\
\hline Antihipertensivos & $\begin{array}{l}\text { Opioides } \\
\text { agonistas }\end{array}$ & $\begin{array}{l}\text { Atividade } \\
\text { antimicrobiana }\end{array}$ & $\begin{array}{l}\text { Atividade } \\
\text { imunomoduladora }\end{array}$ \\
Antioxidantes & $\begin{array}{l}\text { Opioides } \\
\text { antagonista }\end{array}$ & $\begin{array}{l}\text { Carreadores de } \\
\text { minerais }\end{array}$ & $\begin{array}{l}\text { Atividade } \\
\text { antimicrobiana }\end{array}$ \\
Hipocolesterolêmicos & & Modulação celular \\
\hline
\end{tabular}

Fonte: Adaptado de Korhonen e Pihlanto (2006).

Usualmente, são empregadas fórmulas sintéticas constituídas de misturas de aminoácidos livres ou hidrolisados proteicos contendo peptídios de baixo peso molecular, de preferência di e tripeptídios, para o tratamento clínico de pacientes que apresentam complicações gastrointestinais, desnutrição decorrente de processos tumorais, queimaduras ou outros traumas, diarreia aguda ou crônica, alergias alimentares, ou desordens no metabolismo de aminoácidos, como na fenilcetonúria ${ }^{34,39}$. 
$\mathrm{Na}$ alimentação enteral, dá-se preferência aos hidrolisados proteicos, ricos em peptídios de baixo peso molecular, devido à excelente absorção gastrointestinal e a sua baixa osmolalidade, sendo estes melhor utilizados pelo organismo do que as proteínas intactas ou os aminoácidos livres ${ }^{40,41}$.

Outro campo de estudo e de aplicação para os hidrolisados proteicos é a obtenção de peptídios pequenos, biologicamente ativos, os quais podem desempenhar várias funções, regulando ou inibindo a atividade enzimática, atuando como antibióticos, hormônios, agentes antivirais e antibacterianos ou imunomoduladores ${ }^{42}$.

A aplicação dos hidrolisados varia em função da distribuição do peso molecular dos peptídios. Assim, peptídios com pesos moleculares entre 5 e $20 \mathrm{kDa}$ são utilizados geralmente como fontes de nitrogênio, em alimentos para fins especiais e suplementos alimentares para adultos. Já peptídios com pesos moleculares menores que $5 \mathrm{kDa}$ são oriundos de proteínas altamente hidrolisadas, sendo frequentemente utilizados em formulações hipoalergênicas ${ }^{43}$.

Formulações à base de hidrolisados proteicos com alto teor de aminoácidos ramificados (ACR), valina, leucina e isoleucina, e com um baixo conteúdo em aminoácidos aromáticos (AA), fenilalanina e tirosina, podem ser empregadas com sucesso no tratamento dietético de pacientes com lesões hepáticas crônicas, incluindo a encefalopatia hepática. Observou-se que uma relação ACR/AA, denominada de "Relação de Fischer" maior que 3,0, contribui para melhoria significativa no quadro clínico dos pacientes, atribuída à normalização da concentração plasmática de aminoácidos e à manutenção de um aporte proteico adequado ${ }^{44,45}$.

\section{PEPTÍDEOS BIOATIVOS DA SOJA}

A soja constitui um alimento bastante estudado quanto aos seus peptídeos bioativos, sendo estes relacionados, principalmente, às atividades anti-hipertensiva, hipocolesterolemiante, antiobesidade, antioxidante, anticâncer e imunomodulatória ${ }^{46}$.

Os peptídeos bioativos da soja podem estar presentes naturalmente ou ser produzidos por meio da hidrólise das proteínas durante seu processamento industrial. Esses peptídeos são resistentes à digestão e podem atuar como moduladores fisiológicos das funções corporais em relação ao envelhecimento e ao desenvolvimento de doenças crônicas típicas da velhice, tais como câncer, hipertensão, obesidade, hipercolesterolemia e redução da função imunilógica, entre outras. Além disso, os peptídeos bioativos da soja podem retardar o processo de envelhecimento devido à eliminação dos radicais livres e à inibição da peroxidação de lipídios enzimáticos e não enzimáticos ${ }^{47}$.

Entre os peptídeos bioativos da soja, a Lunasina é de longe o mais/melhor estudado e sua eficácia contra carcinógenos químicos e oncogêneses foi demonstrada em células de mamíferos e modelos animais. Lunasina é um peptídeo contendo 43 resíduos de aminoácidos, com 9 Asp carbóxi-terminais, um motivo de adesão celular Arg-Gly-Asp, e hélice com homologia estrutural a região conservada de proteínas ligadoras de cromatina $^{47}$.

A tabela 2 mostra alguns peptídeos bioativos da proteína de soja, com seus respectivos efeitos biológicos observados.

Tabela 2. Estudos com peptídeos bioativos derivados da proteína de soja.

\begin{tabular}{|c|c|c|c|}
\hline Fonte & $\begin{array}{c}\text { Precursor de peptídeo } \\
\text { e/ou peptídeo } \\
\text { identificado }\end{array}$ & Efeito observado & Referência \\
\hline $\begin{array}{c}\text { Farinha de soja } \\
\text { desengordurada }\end{array}$ & $\begin{array}{c}\text { Amostra de } \\
\text { hicrolisado solúvel } \\
\text { foi fracionada com } \\
\text { resina de troca } \\
\text { cationnica }\end{array}$ & Hipotensivo & $\begin{array}{c}\text { Wu e Ding } \\
(2001)\end{array}$ \\
\hline $\begin{array}{c}\text { Proteína de soja } \\
\text { desengordurada }\end{array}$ & $\begin{array}{c}\text { Met-Leu-Pro-Ser- } \\
\text { Tyr-Ser-Pro-Tyr }\end{array}$ & Anticâncer & $\begin{array}{c}\text { Kim et al. } \\
(2000)\end{array}$ \\
\hline Proteína de soja \\
concentrada & $\begin{array}{c}\text { Peptídeos com } \\
\text { diferentes pesos } \\
\text { moleculares foram } \\
\text { separados de } \\
\text { material digerido por } \\
\text { ultrafiltração }\end{array}$ & $\begin{array}{c}\text { Aumento da } \\
\text { captação e } \\
\text { por receptores de } \\
\text { células HEPG2 }\end{array}$ & $\begin{array}{c}\text { Arnoldi et } \\
\text { al. (2001) }\end{array}$ \\
\hline Glicina da soja & LPYPR & $\begin{array}{c}\text { Peptídeo } \\
\text { hipocolesterolêmico }\end{array}$ & $\begin{array}{c}\text { Yoshikawa } \\
\text { et al. } \\
(2000)\end{array}$ \\
\hline B-conglicina & $\begin{array}{c}\text { MITLAIPVNKPGR; } \\
\text { MITLAIPVN; MITL }\end{array}$ & $\begin{array}{c}\text { Imunomodulação } \\
\text { et al. } \\
(2000)\end{array}$ \\
\hline
\end{tabular}


O efeito de peptídeos, preparados a partir da proteína de soja, foram estudados usando a enzima alcalase em ratos hipertensivos ${ }^{48}$. Os resultados sugerem que os peptídeos proporcionaram efeito hipotensivo. Alguns pesquisadores ${ }^{49}$ purificaram e isolaram um peptídeo anticâncer a partir da proteína de soja. Proteína de soja desengordurada foi hidrolisada com thermoase e os peptídeos hidrofóbicos foram extraídos com etanol. O extrato de peptídeo foi fracionado e analisado por cromatografia. A atividade anticâncer de cada fração foi analisada pela medida in vitro da citotoxicidade em P388D1, uma célula macrofágica de rato. A fração de peptídeo de Sephadex G-25 foi 0,16 mg/mL. Essa fração de peptídeo a $1 \mathrm{mg} / \mathrm{mL}$ afetou significativamente o progresso do ciclo da célula, prendendo P388D1 a fase G2/M. Finalmente, o peptídeo purificado por HPLC tinha peso molecular de 1157 Da com sequência Met-Leu-Pro-SerTye-Ser-Pro-Tyr.

Alguns pesquisadores ${ }^{50}$ estudaram amostras de Croksoy ${ }^{70}$, uma amostra comercial obtida tratando uma proteína de soja concentrada extrusada com rápido aquecimento sob alta pressão e submeteram essas amostras a ensaios biológicos, visando avaliar seu efeito sobre o colesterol. Estudos em humanos e em animais têm sugerido que o mecanismo de ação da proteína de soja pode estar diretamente associado à ativação direta dos receptores de LDL (lipoproteína de baixa densidade) em células de fígado. As frações isoladas pela ultrafiltração foram submetidas aos mesmos ensaios biológicos. Os resultados confirmam as propriedades de produtos de soja na redução do colesterol, talvez exercida apenas pelos peptídeos formados durante a digestão.

Vários tipos de peptídeos bioativos que podem atuar na prevenção de doenças são liberados de proteínas de origem vegetal ou animal após digestão enzimática. Peptídeos inibidores da enzima conversora de angiotensina I com efeito anti-hipertensivo tem sido isolado da digestão enzimática de várias proteínas. LKPNM, que foi isolado da digestão da termolisina de bonito desidratado foi ativada e demonstrou um efeito prolongado após administração oral. Dois peptídeos vasorelaxantes, Ovokonin (Phe-Arg-Ala-Asp-His-ProPhe-Leu) e Ovokinin (2-7) (Arg-Ala-Asp-His-ProPhe), com efeito anti-hipertensivo após administração oral foram obtidos da digestão da ovoalbumina. Eles encontraram que peptídeos com baixo peso molecular derivados de proteínas alimentares reduziram o colesterol sem aumentar a excreção de ácidos biliares. Um peptídeo imunoestimulante, isolado a partir de uma digestão enzimática de proteína de soja, impediu a alopecia induzida por quimioterapia ${ }^{51}$.

\section{PEPTÍDEOS ANTIOXIDANTES}

Antioxidantes são definidos como substâncias que, quando presentes em baixas concentrações em relação ao substrato oxidável, são capazes de inibir ou retardar substancialmente a oxidação daquele substrato. Os antioxidantes não se tornam radicais livres pela doação de elétrons, pois eles são estáveis em ambas formas ${ }^{52}$.

Peptídeos ou fragmentos de proteínas são curtas cadeias de aminoácidos produzidos pela hidrólise enzimática ou pela digestão gastrointestinal dos alimentos. Alguns peptídeos possuem funções bioativas, entre elas destaca-se a capacidade antioxidante ${ }^{29}$.

A oxidação afeta lipídeos, proteínas e carboidratos. No entanto, a oxidação lipídica é a principal causa de deterioração de alimentos, levando à redução da vida útil $^{53}$. Dessa forma, a oxidação lipídica é a maior causa de perda de aroma, valor nutritivo e diminuição da vida útil de produtos contendo gordura. Com o intuito de diminuir este problema, antioxidantes sintéticos como butil-hidroxil tolueno (BHT) e butil-hidroxil anisol (BHA) têm sido amplamente utilizados na indústria alimentícia. Porém, os efeitos adversos causados por estes compostos estimularam o uso de antioxidantes naturais, tais como catequinas, tocoferóis, ascorbato, ácido rosmarínico e vários extratos fenólicos de plantas. A procura por antioxidantes naturais se estendeu para proteínas e peptídeos de origem animal e vegetal como proteínas de soja, zeína, gérmen de trigo, albumina do ovo, proteínas lácteas ${ }^{54,55}$.

Os hidrolisados proteicos de soja possuem atividade antioxidante e são capazes de reduzir a oxidação lipídica em produtos cárneos. Estudos mostram que a proteína hidrolisada de soja possui habilidade em inibir o radical livre 2,2-difenil-1-picrilhidrazila (DPPH) e o etilbenztisolina-6-ácido sulfônico (ABTS) ${ }^{55,56}$.

O maior efeito antioxidante da proteína de soja está atribuído a seis peptídeos compostos por 5-16 resíduos de aminoácidos ${ }^{57}$. Peptídeos com massa molecular inferior a $1 \mathrm{kDa}$ e prevalecente de resíduos de aminoácidos aromáticos possuem maior capacidade antioxidante ${ }^{56}$. 
Embora vários estudos tenham mostrado o sequestro de radicais livres, a inibição da peroxidação lipídica e quelação de íons metálicos de transição, o mecanismo responsável pela atividade antioxidante de peptídeos não está completamente esclarecido. As propriedades antioxidantes estão mais relacionadas à composição, estrutura e hidrofobicidade dos aminoácidos ${ }^{58}$.

Oliveira $^{59}$ estudou a hidrólise da proteína de soja através de uma protease produzida por Chryseobacterium $s p$., a fim de verificar a capacidade antioxidante e aplicação do hidrolisado em diferentes tipos de carnes para evitar a oxidação lipídica. A eficácia da hidrólise foi determinada através da proteína solúvel utilizando o método de Folin enquanto que a atividade antioxidante foi avaliada pelos métodos referentes à captura do radical DPPH e ABTS. Os hidrolisados foram adicionados em carne de porco e peixe e foi verificada a inibição da oxidação lipídica. A influência de três parâmetros (temperatura, $\mathrm{pH}$, relação enzima/substrato) na hidrólise foi estudada. Como respostas, foram avaliadas a atividade antioxidante (DPPH e ABTS), atividade quelante de ferro, proteína solúvel, capacidade de formação de espuma e capacidade emulsificante. Observou-se um aumento na concentração de proteína solúvel em função do tempo, sendo que os hidrolisados foram capazes de inibir tanto o radical DPPH quanto o ABTS. Os hidrolisados inibiram em parte a oxidação lipídica em carne suína e peixe. Ainda foi possível concluir que dependendo da finalidade para que se deseja o hidrolisado, diferentes condições devem ser utilizadas. Os resultados demonstram uma potencial aplicação da protease microbiana para gerar hidrolisados antioxidantes da proteína de soja.

\section{PEPTÍDEOS ANTIMICROBIANOS}

Mais de 700 peptídeos antimicrobianos já foram identificados em todas as espécies vivas, incluindo bactérias, fungos, insetos, moluscos, crustáceos, aracnídeos, plantas, pássaros, anfíbios, peixes, mamíferos, entre outros. Em geral, são moléculas pequenas de até 5 $\mathrm{kDa}$ que exibem um alto teor de aminoácidos básicos e, pelo menos, $50 \%$ de aminoácidos hidrofóbicos ${ }^{60}$.

Apresentam um amplo espectro de atividade contra bactérias, fungos, vírus e parasitas. O mecanismo de ação mais bem conhecido é através da sua inserção na membrana celular dos micro-organismos, o que causa a destruição ou a permeabilização dessa, levando o micro-organismo à morte. Alternativamente, os peptídeos antimicrobianos podem se ligar a um receptor da membrana, levando a uma perda específica de sua função. Além disso, ao se translocarem através da membrana, essas moléculas podem atuar intracelularmente, impedindo a síntese de metabólitos importantes para o micro-organismo. Por atuarem em diferentes compartimentos celulares, esses compostos tornam-se candidatos promissores para $\mathrm{o}$ desenvolvimento de drogas importantes no combate a patógenos resistentes aos antibióticos convencionais ${ }^{61}$.

Nascimento $^{62}$ desenvolveu um procedimento metodológico para extrair, purificar e caracterizar bioquimicamente os peptídeos catiônicos antimicrobianos presentes em sementes maduras de soja, e avaliar a ação dessespeptídeoscontraas bactérias Ralstonia solanacearum e Clavibacter michiganensis, visando à utilização desses peptídeos como compostos biologicamente ativos para o controle de doenças em humanos, outros animais e plantas. Os peptídeos de semente madura de soja foram extraídos, na proporção 1:5 (gramas semente:mL tampão), em tampão fosfato de sódio $25 \mathrm{mM}, \mathrm{pH} 7,4$, contendo $\mathrm{KCl}$ $100 \mathrm{mM}$, EDTA $2 \mathrm{mM}$, PVP 1,5\% (p/v), tioureia $2 \mathrm{mM}$, PMSF $1 \mathrm{mM}$ e benzamidina $1 \mathrm{mM}$ por homogeneização do extrato durante 2 horas a $4^{\circ} \mathrm{C}$, em banho de gelo. $\mathrm{O}$ extrato obtido foi centrifugado a $20.300 \mathrm{x} \mathrm{g} \mathrm{a} 4^{\circ} \mathrm{C}$ e o sobrenadante obtido após o final da extração foi fracionado com sulfato de amônio sólido $35 \%$ sat. e centrifugado sob as mesmas condições. $\mathrm{O}$ sobrenadante foi aquecido a $80^{\circ} \mathrm{C}$ por 15 minutos e novamente centrifugado sob as mesmas condições. Após a diálise do extrato em membrana de exclusão de $1.000 \mathrm{Da}$, foram realizadas as cromatografias de troca iônica, de exclusão e a de fase reversa, para obtenção dos peptídeos catiônicos purificados. A análise em espectrômetro de massa das frações eluídas do HPLC indicou a presença de compostos de massas moleculares menores do que $500 \mathrm{Da}, 678,61 \mathrm{Da}$ e 700,60 Da, a presença de peptídeos com massas moleculares de 5.809,11 Da, 8.526,97 Da e 14.113,18 Da. A sequência de aminoácidos do peptídeo de 5.809,11 Da foi determinada e mostrou alta homologia com as cadeias B da pró-insulina humana e de vários outros organismos, da insulina bovina e da insulina de feijão-de-porco (Canavalia ensiformes). Os compostos presentes em dois pools eluídos da cromatografia de exclusão molecular, pool 2 e pool 3, inibiram o crescimento 
da bactéria Gram-negativa Ralstonia solanacearum, enquanto que, para a bactéria Gram-positiva Clavibacter michiganensis, somente o pool 3 exerceu alguma ação, mas com a inibição do crescimento muito menor do que a obtida para a Ralstonia solanacearum. Assim, estes compostos apresentam potencial antimicrobiano a ser explorado na indústria agrícola.

\section{Considerações Finais}

Verificou-se, neste trabalho, que os peptídeos são obtidos pela hidrólise enzimática de proteínas, podendo sofrer alteração no perfil durante o processamento dos alimentos. Isso leva a perspectivas futuras e promissoras, de exploração pela indústria na área de alimentos funcionais. Dessa forma, os peptídeos bioativos a partir da soja, uma das principais culturas agronômicas no Brasil, fonte de proteína vegetal, podem fornecer novas alternativas no âmbito de alimentos funcionais. Assim, é possível otimizar o teor de compostos bioativos em produtos à base de soja, ou adicioná-los a outros produtos alimentícios, ou ainda utilizar na suplementação alimentar. Os peptídeos bioativos, portanto, agregam mais valor econômico e tecnológico à soja, beneficiando os produtores, consumidores e a indústria alimentícia.

\section{Referências}

1. Conab. Companhia Nacional de Abastecimento, 2016. 182 p.

2. Bickel, U. Dissertação, 2003. 169p.

3. Castro, B. S. Dissertação, 2006. 166p.

4. WWF. Produção e exportação de soja brasileira e o Cerrado, 2001.

5. Hartmann, R., Meisel, H. Curr Opin Biotechnol, 2007, 18, 166.

6. Korhonen, H., Pihlanto, A. Int Dairy J. 2006,16, 960.

7. Zhang, L., Li, J., Zhou, K. Bioresour Technol, 2010, 101, 2089.

8. Lang, R. e Kofler, B. The galanin peptide family in inflammation. Neuropeptides, 2011, 45, 1,8.

9. Vivo-Sesé, I. e Pla, M. Anal Cosm. Prod. 2007, 389.

10. Xie, Z., Huang, J., Xu, X., Jin, Z. Agriculture, 2008, 111, 376.

11. Sadick, N.S. Dermatol Clinics, 2014, 32, 1, 21.

12. Cunha, R.C., Espíndola, C.J. GeoTextos, 2015,11, 1.
13. Silva, T.A., Silva, P. B., Silva, E. A. A., Nakagawa, J., Cavariani, C. Cienc. Rural, 2016, 46, 2, 232.

14. Empresa Brasileira de Pesquisa Agropecuária- Embrapa. 2012.

15. Secex - Secretaria de Comércio Exterior. 2014.

16. USDA, United States Department of Agricuture. 2015.

17. Silva, J. M., Mendes, E. P. P. Espaço em Revista, 2012, 14, 1,65 .

18. Mendonça, M. R. Tese. 2004, 457p.

19. Martins, J. S. A chegada do estranho.1997.

20. Pires, L. M. Dissertação, 2007. 13 p.

21. Carrijo E.L.O., Miziara F. Rev. Econ. 2009, 5, 2,121.

22. Bottega, E. L., Queiroz, D. M., Pinto, F. A. C., Márcio, C. Souza, Alves. Rev. Ciênc. Agron. 2013, 44, 1, 9.

23. Roberfroid, M.B. J. Nutr. 2007, 137,3,837.

24. Pacheco, M. T. B.; SgarbierI, V. C. Embrapa, 2001.

25. Angelis, R. C. Arq. Gastroenterol. 2001, 38, 4, 271.

26. FDA. Food and Drug Administration. Fed Reg. 1999, 57,733 .

27. ANVISA. Agência Nacional de Vigilância Sanitária. 2005.

28. Shahidi, F., Zhong, Y. Bioactive peptides. J AOAC Int. 2008, 91, 4, 931 .

29. Dziuba, J., Iwaniak, A., Minkiewicz, P. Polimery, 2003, 48, 53.

30. Kitts, D. D., Weiler, K. Curr. Pharm. Des, 2003, 9, 13091323.

31. Zavareze, E. R., Silva, C. M., Salas-Mellado, M., PrenticeHernández, C., Quím. Nova, 2009, 32, 7, 1739-1743.

32. Cudennec, B., Ravallec-Pléc, R., Courois, E., FouchereauPeron, M. Food Chem., 2008, 111, 970-975.

33. Moller, N. P., Scholz-ahrens, K, E., Roos, N., Schrezenmeir, J. Eur J Clin Nutr., 2008, 47, 171- 182.

34. Clemente, A. Trends Food Sci Tech, 2000, 11, 254-262.

35. Favaron, S. H. F., Ivanov, N. K., Pacheco, M. T. B., Souza, A. S., Silva, V. S. N, Cardozo, G. M. B. Q., Liserre, A. M. EMBRAPA/IAC/ITAL, 2010, 6p.

36. Eça, R.I, Ferreira, I. M. P. L.V.O. Revista da SPCNA, 2006, $12,3,108-119$.

37. Machado, A., Liria, C. W., Proti, P. B., Remuzgo, C., Miranda, M. T. M. Quím. Nova, 2004, 27, 5, 781-789.

38. Samir, P., Link, A. J. The AAPS Journal, 2011, 13, 2, 152-158.

39. Frokjaer, S. Food Technol., 1994, 48, 10, 86-88.

40. Adibi, S. A. J Lab Clin Med., 1989, 113, 6, 665-673. 
41. Siemensma, A. D., Weijer, W. J., Bak, H. J. Trends Food Sci Tech, 1993, 4, 16-21.

42. Gill, I., López-Fandiño, R., Jorba, X., Vulfson, E. N. Enzyme Microb. Technol., 1996, 18, 162-183.

43. Mahmoud, M.I. Food Technol., 1994, 48, 10, 89-95.

44. Bautista, J., Hernandez-Pinzon, I., Alaiz, M., Parrado, J., Millan, F. J. Agric. Food Chem., 1996, 4, 967-971.

45. Fischer, J. E., Bower, R. H. Surg Clin North Am, 1981, 61, 3, 653-660.

46. Wang, W., Mejia, E. G. de. Comp Rev Food Sci Food Safety., 2005, 4, 63-78.

47. Mejia, E. G de., Wang, W., Vasconez-Costa, M., Nelson, R.; Lumen, B. O. 2007.

48. Wu, J., Ding, X. J. Agric. Food Chem., 2001, 49, 1, 501-506.

49. Kim, S. E., Kim, H. H., Kim, J. Y., Kang, Y. I., Woo, H. J., Lee, H. J. BioFactors, 2000, 12, 1-4, 151155.

50. Arnoldi, A., D’agostina, A., Boschin, G., Lovati, M. R., Manzoni, C., Sirtori, C. R. Biologically active phytochemicals in Food, 2001, 269, 103-106.

51. Yoshikawa, M., Fujita, H., Matoba, N., Takenaka, Y., Yamamoto, T., Yamauchi, R. T. H., Takahata, K. BioFactors, 2000, 12, 1-4, 143-146.

52. Hall III, C. A., Cuppett, S. L. AOCS Press, 1997, 141-172.

53. Philanto, A. Int. Dairy J., 2006, 16, 1306-1314.

54. Xue, Z., Yu, W., Liu, Z., Wu, M., Kou, X., Wang, J. J. Agric. Food Chem., 2009, 57, 5287-5293.

55. Zhang, L., Li, J., Zhou, K. Bioresour Technol, 2010, 101, 2084-2089.

56. Beermann, C., Euler, M., Herzberg, J., Stahl, B. Eur Food Res Technol, 2009, 229, 637-644.

57. Chen, H. M., Muramoto, K., Yamaguchi, F. J. Agric. Food Chem., 1995, 43, 574-578.

58. Sarmadi, B. H., Ismail, A. Peptides, 2010, 31, 1949-1956.

59. Oliveira, C. F. de. Dissertação de mestrado, 2011. 85p.

60. Andreu, D., Rivas, L. Biopolimers, 1998, 47, 415-433.

61. Lohner, K. Horizon Scientific Press, 2001, 149-165.

62. Nascimento, D. G. 2003. Tese, 101p.

\section{Carolina S. B. Damasceno, Letícia F. de Oliveira*, Marilis D. Miguel \& Obdulio G. Miguel}

Programa de pós-graduação em Ciências Farmacêuticas, Departamento de Ciências da Saúde, Campus Jardim Botânico, Universidade Federal do Paraná, Curitiba, Paraná, Brasil.

*E-mail: lela-freire@hotmail.com 